\title{
The China Code
}

\section{A Continuum of Twelve Quintessential Chinese Behavioral Characteristics}

\author{
Tom Doctoroff
}

Published online: 5 February 2011

(C) Springer Science+Business Media, LLC 2011

\begin{abstract}
China is evolving - it is becoming modern and international - but its trajectory will never intersect with the West's. Fortunes have waxed and waned over thousands of years, but Chinese civilization has remained apart. Enduring fundamentals - morality rooted in stability, anti-individualism and a micro-analytic, balance-obsessed worldview - both fuel contemporary growth and preclude China's ascendance as a superpower capable of projecting values abroad. A unifying "Confucian Conflict" between trenchant ambition and diffused anxiety also explains the actions and attitudes of ordinary Chinese people. This "street level" article articulates an "insecure or safe" continuum of twelve quintessentially behavioral characteristics that are observed in all realms of contemporary life including diplomacy, business, consumer behavior and social structure. They are: Ritualistic Observation, Robotic Depersonalization, Hierarchical Regimentation, Anxious Self-protection, Trust Facilitation, Pragmatic Elasticity, Incremental Progression, Released Repression, Confidence Projection, Epic Ambition, Scaled Mobilization and Joyful Celebration.
\end{abstract}

Keywords Chinese culture - Confucianism · Daoism . Legalistic $\cdot$ Chinese behavior . Chinese business $\cdot$ Chinese society. Chinese diplomacy and worldview. Chinese consumer behavior . Chinese brands

How does one account for a country of bobbing gold cats, aquariums, red propaganda banners and elevator belches; face fixation, title madness and 35-year-old men living with

T. Doctoroff $(\bowtie)$

25F, The Center, 989 Changle Lu,

Shanghai 200031, China

e-mail: tom.doctoroff@jwt.com mom; germ phobia, amulet mania and savings neurosis; Cantopop cotton candy pap, Hello Kitty shrines and cutesywutesy ring tones; feng shui masters, astronaut husbands, cosmetic surgery contests and grannies hawking sexual aids; glacial currency appreciation, cryptic leadership transition, slow motion contract negotiation and early morning tai qi; gigantic sterile lobbies, EMBA courses for 3 years olds, "holiday economics" and dragon tea ladies; VVVIP cards, neon infatuation, Olympic obsession and title fixation; ultra-violent video games, chat room addiction, rococo bathhouses and SMS mobs; food worship, wedding bedroom booby traps and waltzing after sunset?

China is one country, unified by a near-spiritual belief in something called "Chinese culture." The Han Chinese are more homogenous, more unified, than we give them or they give themselves credit for. Once we understand their culture, a lot of the strange things we see on the sidewalk, in the boardroom, under the table and in supermarkets and malls make a lot of sense. In fact, they are predictable because they conform to a distinctly Chinese worldview. As Sun Tze, author of The Art of War reminds us, anticipation is victory. It can be-it must be-leveraged.

The Chinese worldview translates directly into 12 distinctly behavioral characteristics, what I call The China Code. Any Chinese individual's behavior at any moment will be a function of whether he feels his immediate environment is "dangerous" or "safe." Those behaviors are not random, but fall on a continuum from very fear-based, pessimistic and rigid to very bold, optimistic and expressive.

In order to "succeed" in China on both personal and professional levels, the Chinese worldview and Chinese behaviors must be explored with archaeological rigor and a ruthlessly open mind. All strands of indigenous Chinese philosophy or religion are explicitly geared to the preservation of stability and balance. Daoism teaches that the 
universe has a natural design - as encapsulated in the ba gua - which explains everything from the stars in the sky to the grains of sand on the ground. And man had better accept and snuggly fit into that structure. Confucianism is about societal order. Individuals and inalienable individual rights are not relevant. The basic productive unit of society is the clan. Each Chinese exists somewhere within a very regimented, very intricate hierarchy. That hierarchy mirrors the natural order in heaven. Trouble in the fields means trouble in the stars. Fortune in the bedroom is linked to fortune in heaven. A spoke in that wheel makes the flow wobble and, poof, you're dust. Everything must be aligned lest disaster break out.

In effect, there are two Chinas, Rising China and Falling China. The former is wonderfully alive, expressive, fun, funny and filled with spunk. It's "modern" China. It's the PRC of advertising agencies, Shenzhen entrepreneurialism, intellectually aggressive think tanks, high-tech resourcefulness and ambitious climbing up value chains. Rising China is inspiring, ever changing. Then there is the latter, Falling China. It is a land of blank faces, passive aggressive resistance, numbers on name tags, automated elevator greetings, horrifying provincial airports where the concept of "the customer" simply does not exist. But Falling China is dead. If you land in here, you might as well pack your bags and go home. The forces militating against change are so deeply entrenched that even the noblest warrior will never pierce its rusted heart.

\section{Culture and Chinese Behavior}

Any society that prizes order above all else believes the world is a dangerous place. Given a belief in fate and the cyclical nature of time, good times may not be followed by bad; they will inevitably be. In fact, from bad comes good and vice versa. The deck is stacked against you. Chinese, therefore, are not passive. But they want to protect themselves as they move forward, as they achieve greatness. Chinese behavior, therefore, is both polarized and highly nuanced. Depending on whether one's immediate circumstances are safe, dangerous or somewhere in between, he will behave differently. But it's a continuum of extremes, from cocooned and immobilized to boldly star-reaching, projective, in glorious neon Technicolor.

This article, based on my observations from having lived and worked in China for more than 12 years, identifies 12 distinctly Chinese behavioral characteristics that run the gamut from ultra-rigid to ultra progressive. These twelve "degrees" apply to every Chinese person, although their expression will differ depending on an individual's circumstances. They are:

1. Ritualistic Observation

2. Robotic Depersonalization
3. Hierarchical Regimentation

4. Anxious Self-Protection

5. Trust Facilitation

6. Pragmatic Elasticity

7. Incremental Progression

8. Released Repression

9. Confidence Projection

10. Epic Ambition

11. Scaled Mobilization

12. Joyful Celebration

\section{Ritualistic Observation}

The most rudimentary Confucian imperative is that of "li," or "ritual," pre-cognitive subservience to a prescribed natural order that manifests itself in automatically conditioned behavior. No matter how modern, Chinese are instinctively obedient to Spring Festival rituals-i.e., the New Year, the most important time marker. No sweeping; no washing hair; no vulgar language. If the family is not reunited, heavenly mandate has been violated. Tomb sweeping festival must be observed, lest omnipresent ancestor ghosts howl. Even if liberated by an American Express corporate card, every Chinese is ceremonially correct during important life junctures - new job, marriage, birth and death.

Most pre-monotheistic societies adopt a cyclical view of time to explain the past and predict the future; the Great Wheel is in the stars for all to see. The brilliance of the Chinese worldview is its analytic and diagnostic completeness. Perhaps impelled by the instability of the great Asian land mass - pandemonium from earthquakes, droughts, floods and locusts broke out like clockwork - the Han have meticulously charted the nature of birth, death, time, fortune, disaster, rainfall and everything else since their dawn of civilization. As early as 500 B.C., the elegantly elaborate equations in the "Book of Changes" were accepted as conventional wisdom. Furthermore, heaven and earth were unified, making matters still more complex. The structure of family homes and city layouts mirrors the configuration of the stars; generational progression js syncopated with the flow of time itself. (The emperor's most sacred obligation was maintaining both bureaucratic and cosmological alignment.) No "sane" Chinese challenges this truth, just as no reasonable Westerner questions the existence of gravity. The essence of Chinese universal holism is rarely articulated - few college educated individuals can discuss the $b a$ gua - but manifestations of it are everywhere and affect everything from weddings dates to license plates. (Failure to marry and have a child is shameful, a failure to pay heed to the flow of time).

We often believe Chinese are superstitious, their rituals irrational. Why do such smart people talk so much about 
lucky numbers, amulets and feng shui? But, to the Han, all this is perfectly logical. Every so-called superstition preserves or extends natural order. Chinese health practices-from acupuncture to tai qi-maintains the body's alignment with qi. So do architectural beliefs; feng shui avoids interruption of qi. Gambling, fortune telling, morphology, phrenology and numerology are all addictive because they reveal future qi.

\section{Robotic Depersonalization}

The truly jarring thing about Robotic Depersonalization, the most fear-based - and frustrating - trait of contemporary China is the complete absence of civility. It's almost as if the individual - let alone individualism - simply does not exist. This near animalistic regressive instinct-rooted in a primal belief that people you don't know are dangerous - is the country's most rage-inducing trait. It's a baseline default mechanism, triggered by the absence of opportunity for even the most modest advancement. It is most often observed in dire straits. Cars speed by accident scenes, but will not stop to help the injured. People cut in lines without even a hint of embarrassment. People belch in crowded auditoriums. Women spit, mustering a Richterregistering horccchht, without batting an eyelash. Men urinate in the street, against the wall of lovely buildings, while passers-by look straight ahead. Apartment complexes, particularly ones from the pre-reform era, are Orwellian nightmares, identical mammoth eye sores that go on for miles and miles.

\section{Hierarchical Regimentation}

It is no secret that China is one of the most hierarchical countries on the planet. Volumes can and have been written dissecting this rich topic. The universe boasts an intricate structure, one beyond this amateur cultural anthropologist's grasp. If aligned, stability reigns. If out of kilter, chaos erupts. Earthly order reinforces heaven mandate and vice versa. Adherence to secular hierarchy, therefore, is the first, and most fundamental, imperative consciously accepted by all Chinese. Hierarchy is everywhere: within the family, father always knows best; in schools and universities, teachers brook no dissent; within the government, the power structure is so layered, only the most religiously indoctrinated can navigate the labyrinth; in society, citizen is always subordinate to policy maker. Even Buddhism has been "corrupted" to conform to China's regimentation instinct. There are more Buddhas than summer fire flies, each with his own rank and power. The Chinese are not imprisoned by hierarchy; in a sense, it liberates them, providing enough security to advance within it. Hierarchical clarity is the starting line of forward momentum. The rules of progress are crystal clear, inculcated from birth. The journey of success is a scaled ladder. Progress is achieved by mastering convention.

No Individualism First, let us define terms. Individualism, as opposed to egoism, is the encouragement by society for the individual to define himself independent of society. Bill Gates is admired because he forged a new path, rejecting middle class convention to pursue his own high-tech vision. Madonna is emulated, despite middling talent, because she writes her own rules. In China, this sort of individualism does not exist. It is heretical, a threat to stability. (Underground culture barely exists and is not aspirational.) "Success" has always been linked to mastery of convention (i.e., Confucian canon or Communist dogma). In the West, institutions have developed to liberate the productive power of the individual, ensuring rational allocation of capital. In China, lending decisions are based on edict from on high, not risk assessment. Shanghainese are adaptable to mandates of corporate hierarchy but they are rarely creative. "Entrepreneurialism" is more a question of speedier efficiency (i.e., refining the system) than charting a new course. Pushing new ideas is always risky because it can result in loss of "face," the precious currency that lubricates advancement. Egos are huge; everyone wants to be recognized; but, when the boss is speaking, even the most Westernized employee is scared of raising his hand to ask a question.

\section{Anxious Self-Protection}

Hierarchical societies are, in some ways, safe. They ensure order and lessen the guesswork required to maintain smooth interaction. However, they are also dangerous. If you get kicked down a notch, you lose both money and face, the latter the sociological equivalent of political capital. Dignity is determined by one's place on the totem pole, outside the control of the individual. Banishment from the hierarchyi.e., outcast status - is tantamount to death. The individual does not exist independent of his relationships. Furthermore, in China, the definition of "success" is mandated from on high so the tip of the pyramid is small. Climbing ladders is risky business; competitors are ruthless, desperate for an upper hand. To boot, the PRC's government is still autocratic. Civil rights do not exist; they are not protected by an independent judiciary. Financial interests, including property, are uninsured and the safety net is shredded. Even the new middle class is economically insecure, hanging on to recent gains. 
First, no one takes physical safety for granted. A mother's sacred duty is to protect her children, not rear independent young adults. She is obsessed about germs crawling on soap, invading showers, spewing from air conditioners, clinging to carpet and reproducing in underwear. She is willing to pay $25 \%$ of monthly her income on infant formula, always sold on one immunity claim or another. Omnipresent traffic and security guards reassure, as do guardrails on everything from second-story balconies to street curbs and taxi lines. Books, even newspapers, are wrapped in plastic. Elevators are sterilized every $2 \mathrm{~h}$. The nation will rally to defeat bird flu, SARS and any other virus. The threshold for cancelled airline flights is very low-i.e., scattered thunderstorms and light fog. Paints that do not scream "anti-toxic" will not sell.

Second, no one has faith in the future. The new generation is optimistic but with a "vigilance required" caveat. Saving rates are extraordinary high, currently running at over $40 \%$ of GDP. Yes, rates will decline if and when the financial system becomes more efficient and allocation of resources more rational. However, Chinese will always save more than Americans. The systematic risk of an autocratic, hierarchical society mandates caution. The insurance industry, will take off like a rocket, not as an investment but a hedge against uncertainty. The most "rational" engineer trots to the fortune teller every 6 months, more frequently than he visits the dentist. And parents treat the (single) child as a long term investment, delayed gratification that, unlike the stock market, pays dividends.

In such a self-protective culture, creative release is rare. Local companies do not produce innovative products. Employees never openly stimulate the boss with provocative ideas, at least not face-to-face. (That said, suggestion boxes-i.e., anonymous self-expression-suck in brain storms.) Very few Clio or Cannes awards have gone to home grown advertising talent, partially due to client conservatism but mostly a function of gun shyness. "One kick, one move" is the rule, rather than the exception. Grabbing the brass ring-pushing through boundaries-is dangerous unless the pedestal is stable. Decades from now, China will confront a challenge as it shifts from a production- to a service-based economy, the latter fueled by individual resourcefulness and risk-taking.

\section{Trust Facilitation}

When a Chinese feels "protected," he will begin to forge his life path. He carefully reaches out to people with whom common cause can be established. China lacks institutions that protect individual interests. It is a dog-eat-dog society with 10,000 executions and 110,000 highway deaths every year; trust facilitation, therefore, is a key element of social intercourse.
There are two types of friendships in the PRC: friends of the heart and "wine and meat" acquaintances. The former are bosom buddies, men or women who have maintained relationships since uncorrupted times (i.e., adolescence). Loyalty is tacit but profound; no matter how complicated the world, unconditional acceptance beckons. "Wine and meat" friendships, on the other hand, are not rooted in comfort or struck up spontaneously in bars or at dinner parties and coffee shops. They are choreographed, ultra-civilized minuets that result in mutual benefit. Guys want to get ahead but they do not feel in control. "High risk, high return" has supplanted "no pain, no gain." Adversaries, competitors on an unfamiliar battleground, lurk on the sidelines ready to pounce. Alliances, therefore, are critical. (All liaisons are, until proven otherwise, dangerous.)

Chinese are more at ease with people from their home town than waidiren, or "outsiders." (Mandarin vocabulary is very precise in differentiating degree, or lack thereof, of familiarity.) Men are loath to shed regional accents because, in an ever changing world, "my hometown" remains a source of comforting affiliation. The biggest problem for anyone learning Chinese is the plethora of regional accents. Guys, even young ones who have grown up speaking official putonghua, are harder to understand than women. The Fujianese-Mandarin inflection is almost as unintelligible as the local dialect. Local products such as beer, milk and cigarettes are powerful badges, more emotionally-charged than national and international brands.

Patriarchal societies are tough. Men have the power but they have to prove themselves to women. Marriage is, first and foremost, a commitment, a contract between husband and wife to stand by each other during difficult times. Guys have to justify her love. When we ask women how she knows he loves her, she says, "He would do anything for me." Valentine's Day is de rigueur. Girlfriends leash boyfriends in shopping malls, credit cards dangling from necks. Romance is nice but it ranks third after money and the child. So sex is much more "practical" than in the West. "Sexual aid" stores - note the pragmatism - are everywhere, usually supervised by 60 -year-old ladies that make Dr. Ruth look alluring. Commercialized sex is ubiquitous, low- or high-end; pre-"massage" activities (e.g., sweating in huge saunas, bathing in Grecian Jacuzzis, drinking beers in elephantine cushioned chairs while enjoying a foot massage) are for bonding, letting it all hang out. Wives will divorce if he has an affair. She will grin and bear a night with a call girl.

Faith in Brands Big brands are rooted in trust. Haier, a large appliance behemoth, is popular because of its after 
sales service program. Local banks, despite shoddy service, are embraced because they omnipresent. Still, most international brands are actively preferred due to their international scale and credibility. Most Chinese believe in Intel and Microsoft more than God; both brands are massive, exuding global leadership. (Avis' famous "We try harder" tagline would fall flat in a land comforted by scale.) Stamps of endorsement, germkilling, and anti-toxicity claims are ubiquitous.

\section{Pragmatic Elasticity}

Once the coast is clear, denizens of the Middle Kingdom are spectacularly pragmatic. Their elasticity can be both aweinspiring and disconcerting. In an "ambitiously regimented" society, clever resourcefulness is the most prized personality attribute. Everyone charges ahead while managing to abide by social convention. Barriers are everywhere-life is a game of dodge ball — but the successful evade them. (Anta, a mass shoe brand, has the tagline, "Keep Moving." Even modest Chinese seek progression.)

Chinese resourcefulness, it must be said, has served the nation well. The productive energies of all Chinese are unleashed at the drop of a hat. Marital institutions, as suggested in Chapter X, are also pragmatic. Husbands and wives are willing to spend years living in different cities for professional or material gain. The border city of Shenzhen, a farming village 25 years ago, boasts a population of 5 million. It has evolved in the PRC's "Big Apple," bursting with high-tech wizards and penniless migrant workers. Everyone in Shenzhen, as soon as opportunity rang, made a beeline to a new Entrepreneurial Mecca. Macro-economically, China is much more open to foreign investment than was Japan at a similar point in its development. Culturally, foreign influences are tolerated - even embraced - if they serve Chinese interests. The Han even accepted "barbarian dynasties" as long as governance was rooted in Confucian stricture. When Starbucks opened in the Forbidden City, the nation was not offended; it applauded a savvy integration of East and West.

Pragmatic elasticity has a darker side. China's moral compass has no magnetic north. As yin segues to yang and light fades to dark, right and wrong are always relative. The Chinese world view - typified by the government's cozying up to pariah regimes in order to secure oil contracts - is euphemistically coined "realistic." In a land with few codified laws and ambiguously written legislation, corruption is often accepted as adaptive behavior. Self-serving practicality is amoral. Red packets stuffed with money are given to surgeons to ensure proper attention. Young, aggressive professionals hop promiscuously from job to job, lured by small pay increases.

\section{Incremental Pragmatism}

Human achievement occurs in pre-programmed stages. A man's "journey of success" is an immutable sequence of milestones. In dynastic times, Confucian stricture was explicit: wu shi you wu er zhi yu xue ("set your heart on learning by fifteen"), san shi er li ("be successful by thirty"), si shi bu huo ("have no doubt about yourself by forty"), wu shi er zhi tian ming ("know the mandate of heaven by fifty"), liu shi er er shun ("hear only the mandate of heaven by sixty"), qi shi er cong xing suo bu yu ju ("follow your heart's desire BUT without transgressing the norms") and, from birth to death, guan zong yao zu ("honor and bring glory to ancestors"). Likewise, the requirements for advancement-i.e., a series of tests culminating in the Palace Exam - were meticulously laid out.

Today, entrepreneurialism has complicated matters. But men still progress with precision. First, graduates college. Second, he gets a job. (A respectable salary starts at 3,500 RMB per month with the potential of earning 10,000 RMB by thirty.) Third, by the time he is 28 , he buys an apartment. Fourth, by the time he is 35, he marries. (Few women wed without a 100 square meter flat. Taxi drivers lament, "No money, no honey.") Fifth, he buys a car (a four door sedan) or has a child. Sixth, he has a child or buys a car. Seventh, by forty, he starts his own business. Deviating from this trajectory is suspect.

Women are ambitious too. Her ultimate role remains the "loving and kind protector"; still, she is eager to achieve. But she must never leap; she glides forward. Like a lynx, she slinks ahead step by step, barely noticed by prey. Without graceful femininity, she becomes a freak of nature. Angular vixens, suited in hot red, strutting to the fore, jabbing fingers or pounding fists, do not marry. This accounts for Hello Kitty fixations; cosmetic surgery for big, round eyes; the ubiquity of Snoopy and Sailor Moon paraphernalia; an obsession for doll-like porcelain skin; and addiction to hair alignment shampoo and sexy (cheap) underwear.

\section{Released Repression}

Incremental progression, while productive, happens within regimented social and political hierarchies. Individually and societally, eyes are bigger than stomachs. Everyone wants to advance by leaps and bounds but hops on one foot. Chinese attain liberation from pent up frustration via safe, "approved" surrogates that dot the urban landscape. Aggressive discharges, while occasionally hostile, are rarely rebellious and never challenge the system, the stability of which is essential for pressing forward in the first place. 
The New Generation has more opportunity than at any time in China's history. But, in a Confucian society, individual expression is forever taboo. Youth, are drawn to activities that channel stifled ambition. Voodoo dolls are all the rage. Video-games are much more violent in China (and Korea) than in the U.S. and Europe; titles such as "War of Worlds" flood large cities and small towns. More than 130 million individuals, most under 25, have logged on to the internet, drawn to anonymous, on-line selfexpression There are more than 30,000,000 blogs and bulletin boards spewing invective over everything from Bush's foreign policy gaffes to Nestle milk powder's arrogance. Chatting, popular everywhere in the world, is an obsession in the PRC. Youth develop virtual identities by paying big bucks for on-line fashion accessories and hair styles. Kong Fu's superhero motif glorifies Everyman's hidden power.

Marketers have caught on. In 2005, Mengniu, a Mongolian dairy manufacturer, conducted the most successful promotion in the nation's history, a talent competition a la American Idol. More than 40 million adolescents voted by short message text for "Supergirl," a singer whose flat-chested masculinity violated every definition of conventional beauty. The country, shielded by 21 st century hi-tech anonymity, declared independence from traditional order and, in the process, created a sensation. (The government has now banned SMS contests.)

The New Generation is, more now than ever, connected to the outside world. Yet corrosive nationalism is always just below the surface, ready to boil over given any provocation, perceived or real. Individual ambition is repressed. But demand for national recognition is both insatiable and official policy. The nation is a surrogate identity for tens of millions of striving, frustrated achievers who, in their hearts, proclaim, "China is great so I am too"! Released repression is not always angry. Innocuous, calming oases of relief are ubiquitous. Massage, spas and karaoke parlors, both PG-13 and X-rated, are everywhere, as are oldstyle, sofas with huge cushions. Elaborate bathhouses - huge, neo-Classical or rococo affairs with plaster statues of Greek nymphs in saunas - are found office towers and shopping centers.

\section{Confidence Projection}

Once a Chinese starts to move forward, however incrementally, he must display progress to both himself and society. $\mathrm{He}$ is in too much of a hurry to even think of "rewarding himself." Success is not "real" until other people recognize gains, for two reasons. First, in a culture where anti-individualism reigns, self-esteem is inextricably linked to external acknowledgement. Egos are huge. "Face" is currency. Very few Chinese define identity based on selfactualized satisfaction. Second, the PRC is a competitive, dog-eat-dog environment; everyone scales the same, narrow ladder. By projecting status, territory is marked and adversaries are warned not to mess with someone going to the top. Conspicuous display of power or wealth energizes China; it gives the country pizzazz, a dynamism that led a Japanese friend of mine to observe, "The PRC feels more capitalistic than Japan. It's like a carnival, a big bazaar." Foreigners are either charged up by Middle Kingdom Flash or repelled by it.

Every Chinese flaunts triumph. Those with less experience-i.e., new players desperate to move ahead-do it gaudily, blazing bat signals in the sky. With names like "Build the Country," "Glorious Universe" or "Brilliant Warrior," guys do not walk. They swagger, with one arm weighed down by a gold watch. (Even diamond rings for men sell well in the PRC. The advertising slogan: "One sparkle is enough to make the man"). The stereotype of effeminate Chinese men is a myth; they take their responsibility as provider seriously. They act big and talk bigger, booming commands into Motorola mobile phones. (Guys get shy in unfamiliar environments. But on home turf, they roar.) More is better. Business cards - the thicker, the mightier - display multiple titles and academic degrees. Apartment buildings sport such names as "Rich Gate," "Noble Garden," Tycoon Court" and, my personal favorite, "Gathering of all Heroes Under Heaven." Homes are decorated with neo-classical chintz, Napoleonic bedroom sets and giant chandeliers with lots of light-refracting crystal. Pride is directly correlated to office size. Big bosses love to give tours of their lair, including private bathrooms and me-with-Ministers-XY\&Z photo collections. VIP Cards are passé. VVIP and even VVVIP cards are distributed like coupons.

Singaporeans call mainland Chinese "brand whores," not exactly a put down but, rather, an indicator of budding economic development. Derogatory or not, brands are vital status projectors - identity surrogates - on business and social battlefields. The golden role of marketing to the new Chinese shopper: maximize display. Middle Kingdom subjects are more willing to pay a price premium for goods consumed in public. From a cup of coffee at Starbucks and a slice of foreign pizza to designer mobile phones and torn Levi jeans, penny pinched Chinese will pay a premium for labels other people see. Products used in the home, on the other hand, are usually local and sold at low prices. The Han are not willing to invest in Steuben glass or top-of-theline Toto toilets.

The entire middle class is nouveau riche-after all, economic reforms did not really get rolling after Deng's 1992 Southern Tour - but those farther along learn the art of volume control. Mont Blanc pens-with its conspicuously inconspicuous white star on the tip-are big. 
Likewise, Cartier's classical elegance gets noticed. Today's glitterati prefer diamonds and platinum, the latter sleek and pure, to shiny gold. And the streamlined aesthetic of "Shanghai Chic"-straight lines with a twist of Chinese flair - has been embrace by interior decorators and fashion designers. The rich and powerful show off by not showing off. Instead, these icons, new generation exemplars of Confucian restraint, avoid glitz and, instead, drop pearls of wisdom. One has not arrived until one publishes a secretof-my-success book. The most expensive cognacs and whiskey advertise nuggets of erudition.

"I am China. China is me." The nation's state is a core component of individual self-esteem. To maintain legitimacy, the party must project China's glory to the entire world, shielding the country from indignity and broadcasting success into the ionosphere. Mid-sized companies throw good money after bad on CCTV, China's only national television network, because a country-wide media plan signals strength. Beijing has little charm; distances are vast and taxis are small. But, if nothing else, the capital is imperial. Office buildings are huge, awe-inspiring Dark Star monoliths. Gilded lobbies of public buildings lead to shabby hallways and tin pot bathrooms that always smell bad. Futuristic, thrusting airport facades hide paper-mache walls and rusted toilets. Neon-dazzling, Technicolor, audacious - is everywhere. Rocket launches, the Olympics, chip patents and a Chinese director winning an Oscar are opportunities to extol Middle Kingdom glory. The pageantry of a Communist Party Plenum leaves a Presidential inauguration in the dust.

\section{Epic Ambition}

Once the launching pad has been cleared of debris, the Chinese prepare for take off. An explosion of new opportunity plus age old Confucian drive has created the most aggressive nation in history. There is a sense of "desperate optimism." Polls suggest that most young Chinese are more confident in the future than Americans. And yet no one knows quite how to go about achieving greatness. The "no pain, no gain" credo of dynastic advancement has been replaced with a "high risk, high return" reality. In China's primordial capitalistic universe, the only defense is offense-i.e., developing a pioneering spirit, grabbing opportunities as they whiz by and defeating adversaries.

The Chinese will stop at nothing to get ahead. Parents, particularly since the single child policy, lavish princely sums on the little emperor who is half toddler, half longterm investment. Education is an obsession. A grade B kindergarten course costs more than a year's income. One magnet school recently advertised "MBA training" for 3 year olds. The college entrance exam is a recurring national trauma during which Buddha comes out of the closet. Academic glory is a means to an end, not an intrinsic "good." (Liberal arts majors are frowned upon. If a child is not good in math, he is stupid.) The PRC is not a participatory sporting nation. But if a kid has athletic talent, he will be "hot-housed" from 6 years old, surrendered to soccer boot camp. Westerners want to believe the Communist Party abducts the child and locks him in gymnasiums until his Olympic debut. But Mom and Dad are cheering from the sidelines. Violin lessons, art classes and computer programming camps are alternative success vehicles.

The "Win!" ethic is internalized by adolescence. Job hopping is endemic by 25 . Feet start itching a year without a promotion. Until 2001 a few years ago, go-getter would sell a right arm or left hand to land a Masters in the United States, Europe or Australia. Given the burgeoning opportunity of recent years, a foreign degree, while still fine, is not imperative. Even lowly traffic guards aspire to become Emperor of the Corner. Regardless of whether you are an expat, party apparatchik, street sweeper or starlet, he will chop off feet if you make a step before the light turns green. Cash equals conquest. Shanghai and Beijing 20-somethings flock to cosmetic surgeons to land a premium husband or job. Selfesteem is a moot point. Psychologists are for crazy people.

Sometimes the urge to surge can be destructive or, at least, inappropriate. Even on the road, competition is fierce. In any city, crossing the street is a death trek. Drivers honk and weak, careening around corners, flooring the pedal to beat yellow lights. Pedestrian right of way is a theoretical abstraction. It's a dog eat dog world. Everyone wants to "get there first." The Chinese have chutzpah.

\section{Scaled Mobilization}

Scaled mobilization-individual ambition aggregated on a national level - is perhaps China's greatest competitive advantage. Throughout history - from the (re)building of the Great Wall and Grand Canal to the recent Herculean Olympic project - the country knows how to amass great resources for the collective good. Critically, this urge isn't Japanese bottom-up collectivism, a cultural predisposition in which everyone takes genuine comfort in fitting in. This is top-down, macro-engineering. It's quintessentially Chinese collective confidence, a manifestation of: a) the inseparability of nationalism and individual identity and b) the PRC's readiness to assume its place as a 21 st century superpower.

Large-scale projects are everywhere. China's industrial policy-i.e., it's ruthlessly ambition claw up the value chain - is orchestrated by the bureaucracy. The structure of the telecommunications and information technology 
industries, nurtured in the U.S. by private enterprise and seed money, is government mandated. China's infrastructural ambitions are truly awesome. The highway system, overnight, has spread across the entire nation. By 2020 , there will be 800 modern airports, up from less than a hundred a few years ago.

The "Not in my backyard" syndrome (NIMBY) does not exist. Large swathes of the population are, by fiat, relocated into sterile suburbs miles away from their original community and shockingly few complain. They are really and truly willing to sacrifice for the motherland. (A famous maxim: from 1,000 streams a mighty river flows.) There are two reasons for this. First, the Chinese fear chaos and therefore embrace a strong central government. For them the choice is stark: a strong, ordered, authoritarian China, managed by a legion of technocratic engineers, or implosion. All but the most brazen fringes of society would ever think of organizing dissent unless survival was at stake. Chinese want to be led. Second, the Han are proudly patriotic and fiercely nationalistic. This is driven by individual ambition that rarely finds release. The nation, therefore, serves as surrogate identity for the striver who, on a daily basis, is forced to March in line.

\section{Joyful Humanity}

The Chinese love celebrations, large or small. Foreigners are regarded with wonder. The Chinese are curiously delighted, not Stepfordized. (It is not true that they "always want something"). Despite frustration with soulless Pudong airport or passive-aggressive receptionists, the PRC is warmly vibrant. When safety is assured and progress is real, China lets the good times roll with gusto. When the PRC landed the Olympics, the entire country erupted with glee. During my first trip to Shanghai, the bright, hopeful eyes - the vibrant facial expressions of adults and children on the street-made an indelible impression.

Parks are full of happiness. Old men bond with their chess-playing buddies, laughter spreading over nothing in particular. Boyfriends and girlfriends embrace, unconcerned by the gazes of passers-by. At sunset, people waltz. Hangzhou's West Lake is filled with kites of all shapes and sizes, transforming a pale blue sky into an explosion of color. At concerts, youth lose themselves music, flicking lighters in unison, illuminating darkness. Chinese celebrate today. The flipside of an insecurity-based world view is appreciation of minutae. Small-scale twinkles are as glorious as fireworks. The bionic click-clack of mahjong tiles, muted by the buzz of gossip, is a cacophonous delight. A midnight bowl of noodles can beat sex. (Many Chinese prefer eating to making love.)

The blogosphere is irrationally exuberant. Two lipsyncing-college students who call themselves "Two Chinese Boys" have created a sensation. Slate's Sam Anderson describes the magic: "The boys sit side by side in a dorm room, channeling bubble-gum pop while someone works obliviously behind them at a computer. Their coordination is impeccable, especially during harmonic call-and-response, and they are unparalleled at creating the illusion of really feeling a song's high moments. They're a classic comic duo: The guy on the right is streetwise, fluent in hip-hop hand gestures and facial expressions; his partner is wistful and sensitive (he occasionally pretends to cry). The Two Chinese Boys' emergence as the best lip-syncers in the world may be the surest sign yet that we are passing the superpower torch." Their website's tagline: "Life is short. Make a fool of yourself while you can."

Appreciation of modest pleasure-glorification of the mundane - can help a manager in China. Friday afternoon's milk tea break is genuinely appreciated. Office celebrationsfrom a spontaneous karaoke jam to the elaborate annual banquet —engender loyalty. A modest compliment will touch the heart. The humanity of modern China, unvarnished and ungainly, has made it all worthwhile for this American adman in Shanghai.

In conclusion, the way Chinese think and behave does not need to be mysterious if one accepts their fundamentally different worldview and cultural motivations. If one approaches China with an open mind and heart, the China Code can be cracked, even mastered and the way it shapes consumer culture in China can be better understood.

Tom Doctoroff is Greater China CEO for J. Walter Thompson. He lives in Shanghai, China. He is author of Billions: Selling to the New Chinese Consumer (Palgrave Macmillan), and his most recent book, China Code has appeared in Chinese. 